\title{
Unusually High Fog Frequency at Kushiro, Japan, during Early Autumn in 2012
}

\author{
Shiori Sugimoto \\ Faculty of Environmental Earth Science, Hokkaido University, Sapporo, Japan
}

\begin{abstract}
Fog frequency at Kushiro, Hokkaido Island, Japan, during midsummer depends strongly on the advection of sea fog from the ocean onto the land, which itself depends on the behavior of the North Pacific High (NPH). This study investigates the relationship between unusually high fog frequency at Kushiro during early autumn in 2012 and the NPH extension. The total fog frequency during mid-August through mid-September in 2012 was the highest over the past 32 years. A northwestward expansion of the NPH caused anomalous southerly winds, that transported warm moist air onto the southeast coast of Hokkaido Island. This warm moist southerly flow favors the onshore advection of sea fog, as it does during midsummer. During early autumn in 2012, the warm advection also results in a large temperature difference between atmosphere and sea over the cold Oyashio current, which suggests that an increase in sea fog generation is another important factor for the high fog frequency at Kushiro.
\end{abstract}

(Citation: Sugimoto, S., 2013: Unusually high fog frequency at Kushiro, Japan, during early autumn in 2012. SOLA, 9, 139142, doi:10.2151/sola.2013-031.)

\section{Introduction}

Sea fog is often generated over the western North Pacific during summer because a synoptic-scale southerly wind, caused by anticyclonic circulation around the North Pacific High (NPH) extension, transports warm moist air over the cold Oyashio current, resulting in condensation of water vapor (Lewis et al. 2004; Gultepe et al. 2007b). The synoptic-scale anticyclonic circulation also contributes to the migration of sea fog onto the Pacific coast of Hokkaido Island, northern Japan. For example, interannual variability in midsummer fog frequency as observed at Kushiro, Hokkaido Island (Fig. 1), has shown a long-term decline since 1931 (Sugimoto et al. 2013). This is attributed to large-scale circulation changes in association with the NPH, which control the advection of sea fog onto land. In other words, interannual variability in the NPH is an important driver of variation in fog frequency at Kushiro.

In normal years the NPH starts to retreat eastward at the beginning of autumn, meaning that monthly mean fog frequency at Kushiro shows a gradual decrease from September onwards (e.g., Sawai 1988). The location and extent of the NPH exhibit great interannual variability during its decay phase, and this NPH variability may strongly affect fog frequency at Kushiro during early autumn. However, the relationship between NPH behavior and fog frequency at Kushiro in autumn remains unclear.

The Japan Meteorological Agency (JMA) reported some unusual atmospheric and oceanic features during late summer and early autumn in 2012, as follows; 1) A northwestward extension of the NPH with meandering of the subtropical westerly jet, possibly controlled by processes associated with the south Asian monsoon, typhoons, and cloud convections at the northeast of Philippines, persisted until mid-September, transporting abundant warm moist air over the whole of northern Japan. 2) As a result of the NPH extension, the monthly mean temperature in September 2012 was the highest since 1946 at 51 observation sites in Japan. For example, on Hokkaido Island, the 10-day mean temperatures

Corresponding author: Shiori Sugimoto, Hokkaido University, North 10 East 5, Kita-Ku, Sapporo, Japan. E-mail: shioris@ees.hokudai.ac.jp. (C)2013, the Meteorological Society of Japan.

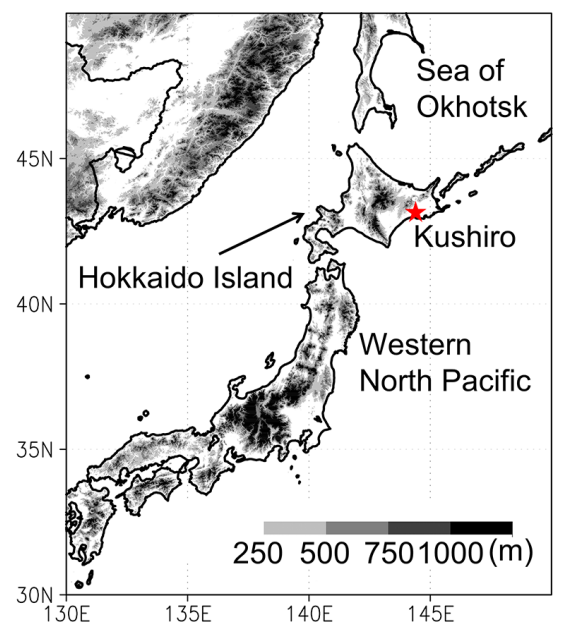

Fig. 1. Topography of the study area. Star indicates the location of Kushiro meteorological observatory.

during early and mid-September were more than 3.0 and $5.0 \mathrm{~K}$ higher than their climatological means, respectively. 3) Sea surface temperature (SST) around Hokkaido Island also increased by approximately 3.5 and $4.5 \mathrm{~K}$ in early and mid-September 2012, respectively, due to the suppression of oceanic vertical mixing and the surface heating associated with the NPH extension. The strengthened warm moist southerly flow of the NPH extension during early autumn in 2012 may have favored advection of sea fog over Kushiro, as shown by Gultepe et al. (2009) and Sugimoto et al. (2013). In addition, the difference in the warming of the air and sea surface might have affected the likelihood of sea fog generation over the ocean due to changes in the stability of nearsurface stratification (Pilié et al. 1979; Dorman et al. 1998; Cho et al. 2000; Koracin et al. 2001; Lewis et al. 2003).

The objectives of this study are to: 1) understand the high frequency of fog occurrence at Kushiro during late summer and early autumn in 2012, and 2) examine the differences between midsummer and early autumn in the contribution of the NPH to fog frequency at Kushiro. The remainder of this paper is organized as follows. Sections 2 and 3 describe the data and analysis method, respectively. Section 4 presents the fog frequency in the 32 years since 1981, and the effects of the large-scale circulation pattern and SST condition on fog frequency at Kushiro in 2012 are discussed in Section 5. Finally, a discussion and conclusions are given in Section 6 and Section 7, respectively.

\section{Data description}

This analysis uses fog frequency reports compiled by the JMA for each 10-day period in every month at Kushiro observatory for 1981-2012. The fog frequency is defined as the number of days when visibility falls below $1000 \mathrm{~m}$ regardless of time or duration, including nighttime. Visibility is measured frequently by traditional visual observation by human observers around the site once fog starts to occur. Fog is distinguished from drizzle, which has an important impact on visibility (Gultepe et al. 2010). Note that in October 2000 the meteorological observatory at Kushiro was redeployed from $\left(42.977^{\circ} \mathrm{N}, 144.387^{\circ} \mathrm{E}\right)$ to its current location at $\left(42.985^{\circ} \mathrm{N}, 144.377^{\circ} \mathrm{E}\right)$. As a result, the new observatory moved approximately $700 \mathrm{~m}$ downwind of the previous location, relative 
to the prevailing southerly wind on fog occurrence days.

The 10-day means of the synoptic-scale circulation pattern in 2012 are calculated from 6-hourly datasets of the Japanese 25year ReAnalysis and JMA Climate Data Assimilation System (JRA25/JCDAS; Onogi et al. 2007). Daily climatological datasets for 1981-2010 are also available, and are used to generate 10-day means of the climatological synoptic-scale circulation. Daily NOAA $1 / 4^{\circ}$ Optimum Interpolation Sea Surface Temperature Version 2 datasets (OISST V2; Reynolds et al. 2007), produced from satellite SST data and in situ data from ships and buoys, are used to analyze SST distribution during 1982-2012.

\section{Analysis of synoptic-scale atmospheric and oce- anic conditions}

Previous studies have revealed that persistent sea fog advection is strongly affected by the low-level winds (Gultepe et al. 2009; Sugimoto et al. 2013). In addition, the difference between the temperature of the low-level atmosphere and SST $(\Delta \mathrm{T})$ is a useful diagnostic tool for identifying the stable stratification associated with sea-fog generation potential (Pilié et al. 1979; Dorman et al. 1998; Cho et al. 2000; Koracin et al. 2001; Lewis et al. 2003). Therefore, to understand the factors responsible for the fog frequency at Kushiro during early autumn in 2012, the synoptic-scale atmospheric circulation pattern at $1000 \mathrm{hPa}$ and the $\Delta \mathrm{T}$ distribution over the cold Oyashio Current are compared with the climatology. In this study, $\Delta \mathrm{T}$ is calculated as the difference between atmospheric temperature at $2 \mathrm{~m}$ and SST.

In addition, this analysis uses the southwest component of the wind vector at $925 \mathrm{hPa}$ averaged over Hokkaido Island, within the area $40^{\circ} \mathrm{N}-45^{\circ} \mathrm{N}, 140^{\circ} \mathrm{E}-145^{\circ} \mathrm{E}$ (SW925), as an index to diagnose the potential for sea fog advection. The SW925 is a useful index to represent interannual variability in summer fog frequency at Kushiro (Sugimoto et al. 2013).

\section{Fog frequency during late summer and early autumn in 1981-2012}

The seasonal variation in monthly fog frequency at Kushiro is shown in Fig. 2a for 2012 and for the 1981-2010 climatology. Monthly fog frequency in winter and spring of 2012 was approximately the same as the climatology. In June and October 2012 the fog frequency anomaly was less than the standard deviation during 1981-2010. However, fog occurred on 20 days in August and 16 in September 2012, more than half of each month. In particular, the fog frequency anomaly for September was approximately twice the standard deviation. Fog frequency was thus significantly higher than the climatology during August and September 2012.

The variation in 10-day total fog frequency in August and September 2012 is compared with the climatology in Fig. 2b. In 2012, fog occurred on 4 out of 10 days in early August, about equal to the fog frequency in a normal year (not shown). However, fog frequency during mid-August through mid-September was greater than in other years (Fig. 2b). The total fog frequency between mid-August and mid-September reached 32 days in 2012, the highest in the past 32 years, even though relocation of the observatory generally resulted in decreased fog frequency after 2000, as shown by Sugimoto et al. (2013). The 10-day total fog frequencies for mid-August, late August, and early September 2012 were each the second highest since 1981. During the 10-day period in mid-September, the 30-yr mean fog frequency for 1981-2010 was approximately 3 days; however, the fog frequency was 9 days in 2012, which is the highest since 1981. The high fog frequency fell to zero in late September (not shown).

The higher fog frequency in 2012 is evident during late summer and early autumn, especially in mid-September, coincident with the period of northwestward extension of the NPH as reported by the JMA. This suggests that the NPH extension causes the unusually high fog frequency. The next section considers differences in the large-scale circulation in the lower troposphere
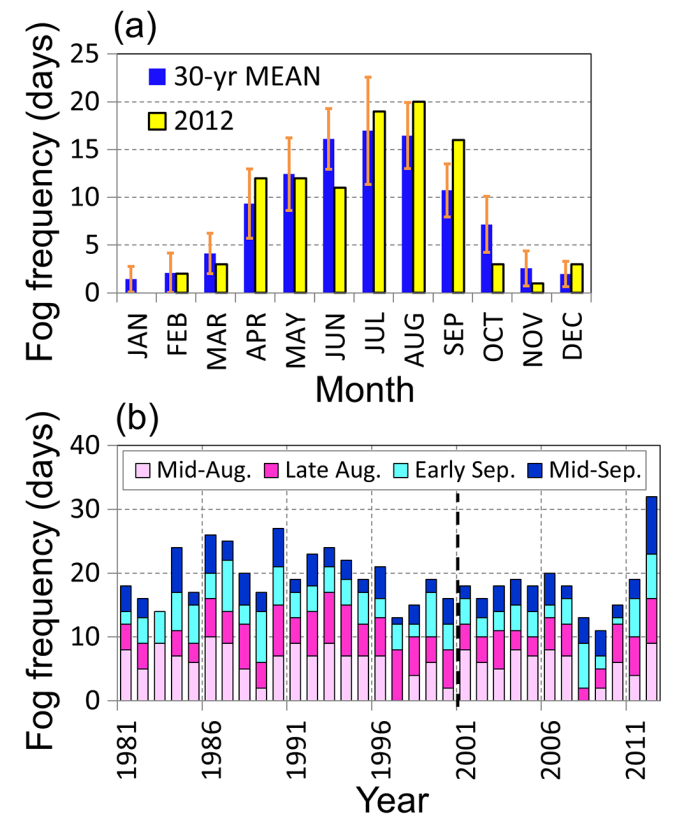

Fig. 2. (a) Seasonal variation in fog frequency at Kushiro averaged during 1981-2010 (blue) with lines indicating one standard deviation, and in 2012 (yellow). (b) Interannual variation in fog frequency within 10-day periods at Kushiro during mid-August through mid-September since 1981.

and the $\Delta \mathrm{T}$ distribution between 2012 and the climatological mean in order to understand sea fog advection and generation in 2012. Particular attention is paid to mid-September because of its remarkably high fog frequency in 2012 relative to normal years.

\section{Atmospheric and oceanic conditions controlling sea fog generation and advection in early autumn 2012}

The climatological synoptic-scale atmospheric circulation at $1000 \mathrm{hPa}$ during mid-September is shown in Fig. 3a. The NPH retreats east of $145^{\circ} \mathrm{E}$ and does not extend over Hokkaido Island. Instead, a cool dry westerly jet prevails over northern Hokkaido Island. The stagnation of moisture flow between the southerly wind at $35^{\circ} \mathrm{N}$ and the mid-latitude jet, which lies offshore of Kushiro, does not favor for sea fog advection toward Kushiro.

In 2012, the NPH remained southeast of Hokkaido Island until mid-September, transporting warm moist air northward across $40^{\circ} \mathrm{N}$ along the western edge of the NPH (Fig. 3b). Gultepe et al. (2009) suggested that for sea fog formation during summer, the more vigorous turbulent fluctuations with stronger warm moist (a)

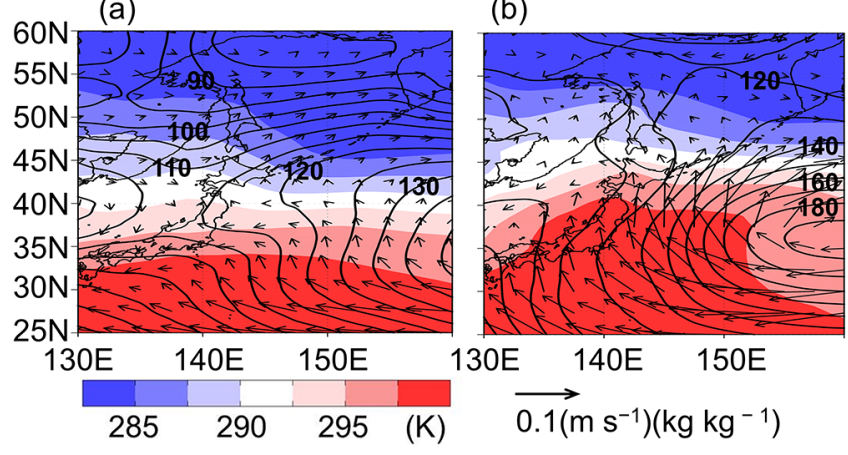

Fig. 3. Spatial distribution of geopotential height (gpm; contours), air temperature (K; shading), and water vapor flux ( $\mathrm{m} \mathrm{s}^{-1} \mathrm{~kg} \mathrm{~kg}^{-1}$; vectors) at $1000 \mathrm{hPa}$ in mid-September for (a) 1981-2010 mean and for (b) 2012. 
(a)

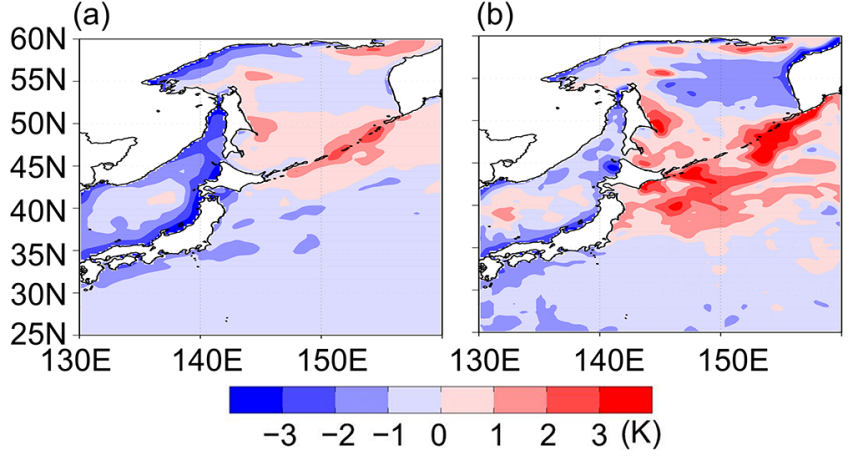

Fig. 4. Same as Fig. 3 but for $\Delta \mathrm{T}$. The climatological mean of $\Delta \mathrm{T}$ is calculated during 1982-2010 due to data availability.

wind cause the increased fog water content as a result of increased moisture, greater availability of condensation nuclei, and mixing of cold dry air above with warm moist air below. Moreover, the relationship between the NPH behavior and fog frequency at Kushiro in mid-September 2012, as shown in Fig. 3b, is in agreement with Sugimoto et al. (2013), who found that summer fog frequency at Kushiro is controlled by the degree of northward advection of sea fog, which itself depends on the position and extent of the NPH. This evidence supports the idea that the strong southerly winds, in association with the northwestward extension of the NPH, contribute to frequent sea fog advection toward Kushiro. Similar large-scale circulation patterns causing anomalous northward transport of warm moist air are also evident during other 10-day periods after mid-August in 2012, especially late August and early September (Supplementary Fig. S1).

The $\Delta \mathrm{T}$ distribution for mid-September (Fig. 4) shows that the climatological $\Delta \mathrm{T}$ is within $\pm 1 \mathrm{~K}$ near the southeastern coastline of Hokkaido Island, which indicates that near-surface atmospheric temperature is close to the SST (Fig. 4a). Note that, $\Delta \mathrm{T}$ is approximately $+3 \mathrm{~K}$ over the Oyashio current in 2012 (Fig. $4 \mathrm{~b}$ ) because the air temperature is $5 \mathrm{~K}$ higher than the climatology, which dominates the SST increase of 2-3 K (Supplementary Fig. S2). Over the area of large $\Delta \mathrm{T}$ in 2012, relative humidity is higher than $90 \%$ (not shown), suggesting that the stable stratification offshore of Kushiro favors sea fog generation during early autumn.

The potential for both sea fog generation and advection was greater in 2012 than in the climatology because of the development of stable stratification and the prevailing warm moist southerly wind. The sensitivity of fog frequency to sea fog generation and advection is examined for late summer and early autumn in 2012 and is compared with that in other years, using the value of $\Delta \mathrm{T}$ averaged over $40^{\circ} \mathrm{N}-43.75^{\circ} \mathrm{N}, 142.5^{\circ} \mathrm{E}-147.5^{\circ} \mathrm{E}$ and SW925 (See Section 3). Relationships between fog frequency, $\Delta \mathrm{T}$, and SW925 are shown in Fig. 5. A significant correlation is found between $\Delta T$ and SW925 regardless of the season (Fig. 5a, b, c, d), which is consistent with the idea that both sea fog generation and advection in 2012 were affected by the large-scale atmospheric circulation. In 2012 (filled circles in Fig. 5), the largest $\Delta \mathrm{T}$ and the second highest SW925 were recorded during mid-September (Fig. 5d). The larger $\Delta \mathrm{T}$ had persisted since mid-August (Fig. 5a, b, c), while SW925 during late August and early September was not significantly higher than in other years (Fig. 5b, c). This suggests that both stable stratification and southwesterly winds were more conducive to fog at Kushiro in 2012 than in other years. In particular, persistent large $\Delta \mathrm{T}$ is likely to have been an important factor for persistent fog occurrence during late summer and early autumn in 2012.

The importance of large $\Delta \mathrm{T}$ during early autumn can be seen in the seasonal variation in $\Delta \mathrm{T}$ shown in Fig. 6. The climatological mean $\Delta \mathrm{T}$ is $1.5-2.0 \mathrm{~K}$ with a standard deviation of approximately $1.0 \mathrm{~K}$ until early August, which indicates that $\Delta \mathrm{T}$ is positive in most years. Under these atmospheric and oceanic temperature conditions, sea fog is likely to be generated almost
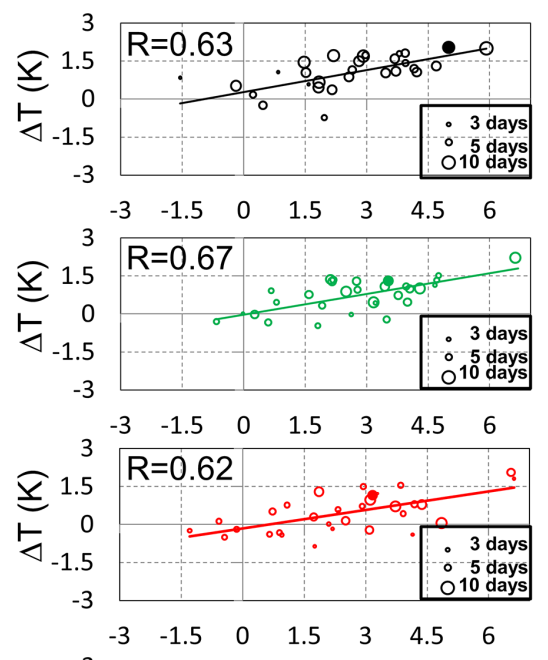

Fig. 5. Scatter diagram

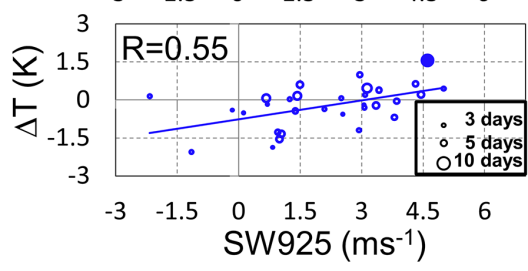
for SW925 and $\Delta \mathrm{T}$ in (a) mid-August, (b) late August, (c) early September, and (d) mid-September during 1982-2012. Size of circles indicates fog frequency for each year. Filled circles indicate 2012. $\mathrm{R}$ indicates correlation coefficient.

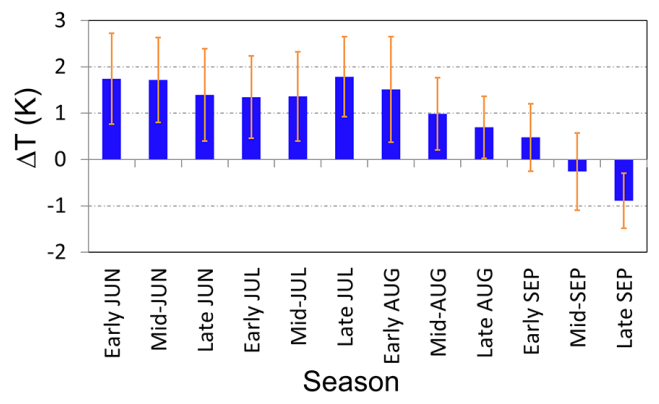

Fig. 6. Seasonal variation in $\Delta \mathrm{T}$ averaged during 1981-2010. Yellow lines indicate one standard deviation.

every day; therefore, during midsummer, the variation in sea fog advection (i.e., SW925) is more important in controlling for fog frequency observed at Kushiro than variation in generation. Meanwhile, $\Delta \mathrm{T}$ gradually decreases after mid-August, turning negative in mid-September. This suggests that during late summer and early autumn, if the period of frequent sea fog generation is prolonged by NPH persistence, much higher than normal fog frequency would be recorded at Kushiro, as in the early autumn of 2012.

\section{Discussion}

Fog frequency at Kushiro during late summer and early autumn in 2012 was influenced by the generation and advection of sea fog associated with the NPH position and extent. However, fog frequency during early autumn in other years did not always depend on $\Delta \mathrm{T}$ and SW925 (Fig. 5a, b, c, d), and fog days were observed even if $\Delta \mathrm{T}$ was negative, which should in fact prevent sea fog generation, especially after late August (Fig. 5b, c, d). The climatology shows two prevailing wind directions at Kushiro on fog days in September (Fig. 7a): between north-northeast and northeast (i.e., from the land to sea) and southerly winds from the ocean, which is different from the fact that southerly winds were dominant in September 2012 (Fig. 7b). This evidence suggests that other fog formation processes (e.g., radiation fog) are im- 


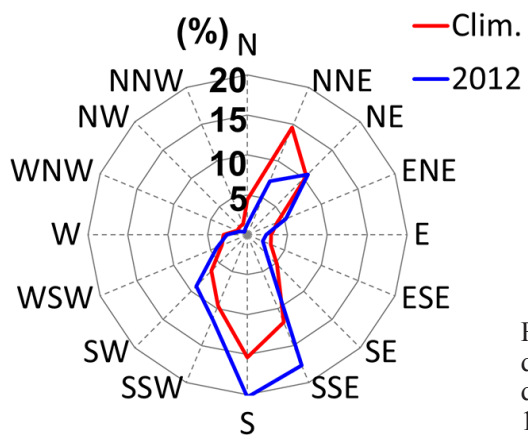

Fig. 7. Frequency of wind direction at Kushiro on fog days during September in (a) 1981-2010 and (b) 2012. portant at Kushiro from late summer onward in normal years, in contrast to the prevailing advection of sea fog in association with the warm moist southerly wind in 2012 .

We also need to discuss the favorable NPH extension and intensification to cause the increase in fog frequency at Kushiro. The interannual variations in $\Delta \mathrm{T}$ and SW925 from mid-August to mid-September were not significantly correlated with strength of the NPH over the western North Pacific (defined as geopotential height at $1000 \mathrm{hPa}$ averaged over $35^{\circ} \mathrm{N}-42.5^{\circ} \mathrm{N}, 140^{\circ} \mathrm{E}-150^{\circ} \mathrm{E}$; not shown), except for SW925 in mid-September. This result implies that the interannual variability in warm moist air transport and the stable stratification over the ocean are unlikely to just depend on the NPH development. In other words, it is necessary to consider whether the shape, extent, and position of the NPH are appropriate for the transport of warm moist air to northern Japan and the increase in fog frequency at Kushiro.

The intensified (weakened) NPH is known to be related to the occurrence of hot (cool) summers in Japan. The interannual variation in summer fog frequency (June-August) shown by Sugimoto et al. (2013) indicates that years with a low fog frequency coincide with years of low summer temperature associated with a weaker NPH (e.g., 1988, 1991, 1993, 2003, and 2009), although this relationship does not always hold in early autumn (Fig. 2b). However, there is no significant relationship between years with hot summers and high fog frequency. This evidence also supports the idea that fog frequency at Kushiro does not simply depend on the NPH extension and intensification described above.

\section{Conclusions}

We have examined the relationship between fog frequency at Kushiro and the large-scale atmospheric circulation pattern between mid-August and mid-September 2012. The following conclusions are drawn from this work.

1) The 10-day total fog frequency at Kushiro was high during late summer and early autumn in 2012, especially in midSeptember when the highest fog frequency in the past 32 years was recorded.

2) This notably high fog frequency was caused by persistence of the northwestward extension of the NPH over the east of Hokkaido Island, which greatly enhanced a warm moist southerly flow in the lower troposphere.

3) The anomalous warm moist air transport from the south favored both sea fog generation over the ocean and its advection into the coastal area. In particular, continuous large $\Delta \mathrm{T}$ resulted in active sea fog generation until mid-September, which strongly contributed to the unusually high fog frequency in 2012.

Interannual variation in fog frequency at Kushiro during autumn is likely to be affected by both sea fog advection and radiation fog, as suggested in Section 6. Satellite images and the result of high-resolution numerical simulations, as well as intensive observations of microphysical parameters, can all help to understand the variation in dominant fog type during autumn and to forecast the local-scale atmospheric environment on autumn fog days, as shown by Gultepe et al. $(2006,2007 a)$.

\section{Acknowledgements}

This work was supported by the Research Program on Climate Change Adaptation (RECCA) of the Ministry of Education, Culture, Sports, Science and Technology (MEXT), Japan, and by a Grant-in-Aid for Scientific Research on Innovative Areas (25106701) funded by JSPS. Fog frequency data were provided by the JMA. JRA-25/JCDAS datasets were provided by the cooperative research project of the JRA-25 long-term reanalysis by the JMA and the Central Research Institute of Electric Power Industry (CRIEPI). OISST V2 SST data were provided by the National Climatic Data Center (NCDC). The author thanks Dr. Tomonori Sato of Hokkaido University for helpful discussions and comments.

\section{Supplements}

Supplement 1 describes a synoptic-scale circulaton pattern before early September for climatology and 2012. Supplement 2 describes differences in air temperature and SST between 2012 and climatology.

\section{References}

Cho, Y.-K., M.-O. Kim, and B.-C. Kim, 2000: Sea fog the Korean Peninsula. J. Appl. Meteor., 39, 2473-2479.

Dorman, C. E., L. Armi, J. M. Bane, and D. P. Rogers, 1998: Sea surface mixed layer during the 10-11 June 1994 California coastally trapped event. Mon. Wea. Rev., 126, 600-619.

Gultepe, I., and J. A. Milbrandt, 2010: Probabilistic parameterizations of visibility using observations of rain precipitation rate, relative humidity, and visibility. J. Appl. Meteor. Climatol., 49, 36-46.

Gultepe, I., M. D. Müller, and Z. Boybeyi, 2006: A new visibility parameterization for warm-fog applications in numerical weather prediction models. J. Appl. Meteor. Climatol., 45, 1469-1479.

Gultepe, I., M. Pagowski, and J. Reid, 2007a: A satellite-based fog detection scheme using screen air temperature. Wea. Forecasting, 22, 444-456.

Gultepe, I., R. Tardif, S. C. Michaelides, J. Cermak, A. Bott, J. Bendix, M. D. Müller, M. Pagowski, B. Hansen, G. Ellrod, W. Jacobs, G. Toth, and S. G. Cober, 2007b: Fog research: A review of past achievements and future perspective. Pure and Appl. Geophy., 164, 11211159.

Gultepe, I., G. Pearson, J. A. Milbrandt, B. Hansen, S. Platnick, P. Taylor, M. Gordon, J. P. Oakley, and S. G. Cober, 2009: The fog remote sensing and modeling field project. Bull. Amer. Meteor. Soc., 90, $341-359$.

Koracin, D., J. Lewis, W. T. Thompson, C. E. Dorman, and J. A. Businger, 2001: Transition of stratus into fog along the California coast: Observations and modeling. J. Atmos. Sci., 58, 1714-1731.

Lewis, J., D. Koracin, R. Rabin, and J. Businger, 2003: Sea fog off the California coast: Viewed in the context of transient weather systems. J. Geophys. Res., 108(D15), 4457, doi:10.1029/2002JD002833.

Lewis, J., D. Koracin, and K. T. Redmond, 2004: Sea fog research in the United Kingdom and United States. Bull. Amer. Meteor. Soc., 85, 395-408.

Onogi, K., J. Tsutsui, H. Koide, M. Sakamoto, S. Kobayashi, H. Hatsushika, T. Matsumoto, N. Yamazaki, H. Kamahori, K. Takahashi, S. Kadokura, K. Wada, K. Kato, R. Oyama, T. Ose, N. Mannoji, and R. Taira, 2007: The JRA-25 Reanalysis. J. Meteor. Soc. Japan., 85, $369-432$.

Pilié, R. J., J. Mack, C. W. Rogers, U. Katz, and W. C. Kocmond, 1979: The formation of marine fog and the development of fog-status systems along the California coast. J. Appl. Meteor., 18, 1275-1286.

Reynolds, R. W., T. M. Smith, C. Liu, D. B. Chelton, K. S. Casey, and M. G. Schlax, 2007: Daily high-resolution blended analyses for sea surface temperature. J. Climate, 20, 5473-5496.

Sawai, T., 1988: Sea fog in Kushiro District (in Japanese). Tenki, 35, $555-566$.

Sugimoto, S., T. Sato, and K. Nakamura, 2013: Effects of synoptic-scale control on long-term decline trends of summer fog frequency at the Pacific side of Hokkaido Island. J. Appl. Meteor. Climatol., in press.

Manuscript received 17 June 2013, accepted 23 August 2013

SOLA: http://www.jstage.jst.go.jp/browse/sola/ 